\title{
Correlating energy consumption with multi- unit residential building characteristics in the city of Toronto
}

\author{
Touchie, M. F., Binkley, C., \& Pressnail, K. D. \\ Version Post-print/accepted manuscript \\ Citation Touchie, Marianne F., Binkley, Clarissa, Pressnail, Kim D. (2013). \\ (published version) Correlating energy consumption with multi-unit residential building \\ characteristics in the city of Toronto. Energy and Buildings 66, pp. 648- \\ 656, doi: 10.1016/j.enbuild.2013.07.068. \\ Additional publisher The final version of this article is available from Elsevier at \\ information https://doi.org/10.1016/j.enbuild.2013.07.068. \\ Copyright/License \\ (c) (1) $\bigodot_{\mathrm{Br}}$ This work is licensed under the Creative Commons \\ International License. To view a copy of this license, visit \\ http://creativecommons.org/licenses/by-nc-nd/4.0/.
}

How to cite TSpace items

\begin{abstract}
Always cite the published version, so the author(s) will receive recognition through services that track citation counts, e.g. Scopus. If you need to cite the page number of the author manuscript from TSpace because you cannot access the published version, then cite the TSpace version in addition to the published version using the permanent URI (handle) found on the record page.
\end{abstract}

This article was made openly accessible by $U$ of $T$ Faculty. Please tell us how this access benefits you. Your story matters. 


\section{Correlating Energy Consumption with Multi-Unit Residential Building Characteristics in the City of Toronto}

Marianne F. Touchie (corresponding author), Department of Civil Engineering, University of Toronto

Clarissa Binkley, Department of Civil Engineering, University of Toronto

Kim D. Pressnail, Department of Civil Engineering, University of Toronto

Corresponding author contact details: +14166686408, marianne.touchie@mail.utoronto.ca. Department of Civil Engineering, University of Toronto, 35 St. George Street, Toronto, Ontario, Canada, M5S1A4

\section{Abstract:}

Multi-unit residential buildings (MURBs) in City of Toronto, Canada, contain more than half of the dwellings in the City and are responsible for a significant proportion of the greenhouse gas (GHG) emissions associated with building energy-use in the residential sector. To efficiently reduce the impact of this sector, MURBs with the highest energy intensity need to be identified. Accordingly, this study examined correlations between building characteristics and energy use. A wide range of energy intensities were revealed and it was found that typology-specific energy-use trends could not be established. The energy intensity variability was attributed to differences in building operation and it was suggested that many buildings can realize improved energy performance by changing operating procedures. The building characteristics exhibiting the strongest correlations with energy use were fenestration ratio and boiler efficiency. However, the need for more uniform and complete building characteristic and energy use data was identified. This study concludes with recommendations to improve the quantity and quality of MURB energy-use data and building characteristics so that researchers can develop a more accurate and complete picture of the MURB energy-use in Toronto.

Key words: multi-unit residential building, energy intensity, energy retrofit, weather-normalization, energy-use data base

\section{Background}

The City of Toronto, Canada, is second only to New York City in terms of the total number of high-rise residential buildings [1]. Not surprisingly, these multi-unit residential buildings (MURBs) comprise $55 \%$ of the dwelling units in the City of Toronto [2]. It has been estimated that Toronto MURBs emit over 2.6M tonnes of $\mathrm{eCO}_{2}$ annually due to the combined electricity and natural gas consumption of these buildings [2], or more than 
$17 \%$ of the total annual greenhouse gas (GHG) emissions associated with natural gas and electricity consumption in the City in 2004 [3]. Thus, MURBs contribute significantly to the environmental impact of residential building energy use in the City of Toronto.

With over 2,000 mid- and high-rise MURBs and approximately 4,000 MURBs with fewer than five stories [2], this vast building stock represents a tremendous opportunity to reduce energy use and the resulting GHG emissions. Toronto has ambitious GHG emission reduction targets of 30\%, based on 1990 levels, by 2020 [4] so MURB energy retrofits are a natural course forward to reducing emissions in the residential sector.

\subsection{Objective}

This study was undertaken to determine how to easily identify MURBs with the highest energy intensity. In doing this, buildings with greatest environmental impact could be targeted first in order to efficiently reduce the impact of the MURB stock as a whole. To accomplish this objective it was necessary to determine the energy intensities of a large sample of MURBs and then to establish the building groups with the highest energy intensities. This way, policy recommendations targeting those groups with the highest energy intensities could be developed.

\subsection{Approach}

Many Toronto MURBs were designed and built during the 1960s and 1970s and, therefore, they exhibited similar architectural features and mechanical system characteristics. Accordingly, this study examined correlations between building typologies and energy use. Correlations between normalized energy use and building characteristics were sought using two distinct data sets. The preliminary data examined included buildings from three existing databases. A meta-analysis of this data was carried out, and it was concluded that additional energy data and more complete details about building characteristics were needed. A second, refined data set was assembled from the best quality data in the meta-analysis data set and then supplemented with buildings that were new to the study. Since this refined data set contained more detailed and comprehensive building information, it became possible to examine how various building characteristics, previously unexplored in the meta-analysis, affected energy use. The results of the search for correlations between similar basic building characteristics and energy use are reported here and the significance of the findings discussed. This paper 
concludes with a series of recommendations for researchers and policy makers on building energy data collection strategies and benchmarking practices so that better quality data can be used to develop policy interventions to efficiently reduce energy-use and GHG emissions in existing MURBs.

\subsection{Previous work}

A number of other studies, based on consumer-supplied energy data of MURBs in the Greater Toronto Area, have sought correlations between energy intensity and various characteristics such as building vintage, height and floor area. In these studies, which included less than 100 buildings, one showed no significant correlations [5] while another discussed observed correlations between energy intensity and building height, gross floor area and vintage without detailing the strength of these correlations [6]. Two studies showed a negative correlation between energy intensity and floor area [7-8]. One of these studies also indicated that privatelyowned buildings, as opposed to public housing, had higher average energy intensities than public housing and that buildings heated with natural gas exhibit higher average energy intensities than those heated electrically [8]. Another study from the west coast of Canada and two other international studies were also examined. A study of 39 MURBs in British Columbia, found that buildings constructed after the 1990s used more energy than older buildings [9]. A Swedish study of 22 new buildings featuring similar design and construction showed correlations between MURB energy intensity and building shape factor and the size of the common areas [10]. A Korean study [11] found that energy use also varied according to the building shape as well as whether the building housed commercial space.

In this study, researchers sought a larger sample size compared to the previous investigations, described above, with the aim of developing stronger correlations. To the authors' knowledge, this work is the only Toronto-specific published study that examines correlations between energy use and envelope and mechanical system characteristics. These more detailed correlations are important for properly identifying the largest contributing factors to energy intensity. By identifying these factors, retrofit measures can be prioritized and new building code measures, such as decreased fenestration ratios, can be supported. Finally, all results have been normalized to the Canadian Weather for Energy Calculations (CWEC) so that other researchers can easily use these data to build upon this work in the future. 


\section{Building Characteristics and Energy-Use Data}

Data were assembled from three existing data sets to form the Meta-Analysis Data Set and were later supplemented with more detailed data to form the Refined Data Set. The characteristics of each data set are presented here along with details on how the data sets were used and the limitations that must be considered when reviewing the analysis.

\subsection{Meta-Analysis Data Set}

In order to build on the work of others, existing MURB energy use data sets were sought. The MetaAnalysis Data Set combined energy use data and basic building characteristics from three different data sources. These existing data sets were derived from: the Canada Mortgage and Housing Corporation's “High-rise Building Statistically Representative" (HiSTAR) Database and the Toronto Atmospheric Fund's Green Condo Champions Program and Tower Renewal Benchmarking Initiative.

This combined data set included 108 buildings, which represented an estimated $4.8 \%$ of the entire mid-and high-rise population and $1.8 \%$ of the total MURB population in Toronto [12]. Building construction dates ranged from 1941 to 2009 . Building heights ranged from four to 46 storeys and gross floor areas ranged from $2,000 \mathrm{~m}^{2}$ to $101,700 \mathrm{~m}^{2}$

Considering the building heights and vintages sampled, the inventory from both the Meta-Analysis data set and the Refined data set can be compared to an estimate of the entire MURB population in Toronto as shown in Figure 1. The "percentage of sample" refers to the proportion of the total number of buildings in the particular data set that fall within a given category. Similarly, the "percentage of population" refers to the proportion of the total number of buildings in Toronto that fall within a given category. If the "percentage of sample" is larger than the "percentage of population", then that category is over-represented in the sample and vice versa.

The data for the number of Toronto buildings in each height and vintage category has been calculated by adjusting data derived from the TObuilt database [2]. The TObuilt database is an online resource which houses information on building characteristics for 1,530 high-rise MURBs (greater than eight stories), and 125 mid-rise MURBs category (five to eight stories). 
Limitations of the Meta-Analysis Data Set include a slight over-representation in the mid-rise category and a slight under-representation in the high-rise category. In terms of building vintage, the Meta-Analysis Data Set significantly over-represents the population of buildings constructed between 1981 and 2000.

With respect to the quality of the data, portions of the Meta-Analysis Data Set were incomplete or missing and the building characteristics data were not sufficiently detailed. In some cases, monthly electricity data were not available or only annual natural gas and electricity data were provided. Additionally, the Meta-Analysis data generally lacked information about mechanical system efficiencies and building envelope details.

\subsection{Refined Data Set}

A Refined Data Set, composed of 40 buildings, was assembled to address the data limitations of the MetaAnalysis Data Set. More complete energy consumption data and information about building characteristics including parameters such as fenestration-to-wall ratio, envelope thermal resistance and mechanical equipment efficiency were available for these buildings.

The Refined Data Set included 20 buildings from the Meta-Analysis Data Set and 20 new buildings including: two that were the focus of a study by Tzekova et al. [13]; three that were the subject of a community energy plan for the City of Toronto [14]; and 15 that were obtained from energy audit reports conducted by engineering consulting firms for projects being carried out by the City of Toronto's Tower Renewal Office.

This smaller Refined Data Set represented $1.9 \%$ of the mid and high-rise population and $0.7 \%$ of the entire MURB population in Toronto. The buildings had construction dates from 1960 to 2003 and ranged in height from five to 28 storeys. The sample buildings varied in size from 24 to 250 suites.

Overall, the Refined Data Set sample distribution of building height, also shown in Figure 1, was similar to the Meta-Analysis distribution. But, as with the Meta-Analysis Data Set, there was an over-representation of newer buildings from the 1990s.

\subsection{Data Set Usage and Sources of Error}

Both data sets were analyzed to determine correlations between building characteristics and energy use. As maximizing the number of buildings included in each correlation was a priority, the larger Meta-Analysis Data Set was first examined for correlations with readily available building characteristics such as vintage, size and 
occupancy type. The Refined Data Set was then used to seek correlations with certain building envelope and mechanical system properties. The Meta-Analysis correlations were repeated for the Refined Data Set to ensure there were no significant differences between the data sets.

\subsubsection{Energy Intensity Determination}

Most of the correlations were sought with respect to energy intensity. The energy intensity of each building was determined by dividing the total weather-normalized energy consumption by the gross floor area. The gross floor area represents the total area containing residential suites, lobby, common areas, and any conditioned recreational areas. It typically did not include underground parking areas even though this space is at least partly conditioned in many buildings.

It is important to note that the method used to obtain the gross floor area reported in the data sets is not known. One publication cited that, depending on the calculation method, the floor area of a building can vary by up to $20 \%$ [10]. Often, the gross floor area is estimated from floor plans of the building, from physical measurements of the building, or from values obtained from real estate information. These methods may not yield accurate measurements of total floor area. The most accurate gross floor area information is likely to exist for condominiums since this information is important for subdividing ownership of the building.

In order to determine the energy use per suite, the average suite size was needed. Detailed data on various suite and common space areas was not available so the authors used an "attributed" suite size rather than the actual suite size. The average attributed suite area was estimated by dividing the gross floor area by the number of suites. This average attributed suite area will be larger than the actual average suite size because it also includes a proportion of the common areas.

\subsubsection{Sources of Error}

The accuracy of the energy intensity values may be affected by errors in the estimated gross floor area as well as by the use of the average attributed suite floor area. Additionally, if the underground parking area is conditioned but not included in the gross floor area, the energy intensity based on the occupied space of the building will be overestimated. The effect of an inaccurate estimation of the floor area of conditioned space will be diminished with a larger data set as errors offset one another; however, more detailed data are generally required 
with respect to whether parking garages are included in the gross floor area and whether these spaces are conditioned.

Information about the building characteristics used in the correlation analysis of the Refined Data Set was gathered from energy audit reports for each building. Building information was collected by more than 12 different individuals as part more than seven different engineering consulting firms. The practices and the assumptions made by each firm vary, and the judgment of each individual may contribute to inconsistencies and variability in the data. Since the energy data and building information were not collected specifically for this study and since information was not necessarily recorded with the aim of being directly comparable with other data sources, the data were scrutinized for inconsistencies. It is possible that some of the data, such as fenestration ratio and boiler efficiencies, were estimated as opposed to actually measured because data sources were not generally identified in the audit reports.

In order to minimize the effect of these errors, further research was conducted. For example, supplementary data sources such as photographs of the buildings obtained through internet searches were used to verify information such as the fenestration ratio, the presence of balconies and through-wall slabs, the general type of wall construction, the number of floors, as well as the window air conditioning units and roof-top equipment such as make-up air units. Building address searches were used to obtain more information about the ownership type and the presence of amenities such as pools or fitness facilities. Finally, census information combined with the number of suites was used to estimate the average number of occupants per suite. However, it is important to note that, even with an accurate estimate of the number of occupants, occupant behaviour will always vary. For example, energy-use profiles vary between buildings that house young families compared to buildings that house senior citizens. Obviously, census information by tract cannot provide the necessary building-level detail about occupant profiles.

\section{Data Processing Procedure}

From building to building, the energy data varied according to location, billing periods and billing years. 
Therefore, normalization was required to account for these variations. The normalization processes applied depended on the data characteristics and was different for each data set. A spreadsheet program was used for all of the normalization processing.

\subsection{Data Normalization}

Three different normalization processes were undertaken: calendarization, normalization of total energy consumption and finally, weather normalization.

Calendarization was carried out to allow buildings with different billing cycles to be directly compared. Meter reading dates were used to apportion energy use to a particular calendar month.

For one data source, total consumption normalization was required when the sum of the monthly energy consumption did not equal the total annual consumption provided. One of the reasons this "difference" can occur is because utility companies will sometimes estimate consumption and make a subsequent adjustment based on an actual meter reading. This discrepancy was minimized by distributing the "difference" equally among the months of the affected year before the weather normalization process was started. In all cases, where total consumption normalization was required, the adjustment did not change the total annual consumption by more than $2 \%$.

The energy consumption data were collected from a range of years for buildings in the Greater Toronto Area. Weather conditions vary from year to year and location to location thereby influencing energy use. Thus, energy consumption data must be weather normalized to a common year and location to allow for comparison between buildings. The weather normalization process involved the following steps:

1. The monthly degree-days were plotted against the monthly energy consumption for all of the available months of data, as shown in Figure 2.

2. Linear regression was then used to determine a line-of-best fit for the data.

3. The coefficient of determination or the " $\mathrm{R}^{2}$ value" of the linear regression was used determined to indicate how well the degree-days explained the building energy use.

4. The equation of the line-of-best fit was then used to determine the energy consumption over a "standard weather year." This was done by inputting the monthly degree-day data from the standard weather year 
into the line-of-best fit equation in order to determine the resulting standard monthly energy consumption.

5. The sum of the monthly energy consumption represented the weather-normalized annual energy consumption value.

The historical monthly Heating Degree-Day (HDD) and Cooling Degree-Day (CDD) data were obtained from Environment Canada for the applicable locations and years. All degree-days for both historical weather and the standard reference year were calculated with an $18^{\circ} \mathrm{C}$ base, based on the assumption that heating is not required until the exterior temperature falls below this base [15]. The standard weather year was based on data from the Canadian Weather for Energy Calculations (CWEC) database. The CWEC data used in this paper were based on Toronto mean temperatures from 1960-1989.

HDD were used for the natural gas weather normalization while three separate correlations were performed with electricity data to capture the possible use of electricity for both heating and cooling. The three correlations included monthly electricity consumption plotted against 12 months of HDD, 12 months of CDD, and a composite 6-month HDD (November through April) and 6-month CDD correlation (May through October). The resulting trend with the highest correlation coefficient was used for the normalization. If either the 6-month HDD or 6-month CDD regression resulted in the best correlation, the electricity consumption data were normalized by a composite of six months of HDD and six months of CDD.

\subsection{Data Classification}

Following weather normalization, further data processing of the Refined data set was necessary before determining the influence of building characteristics on energy use. This additional processing of the Refined data set was completed because the more detailed data available in this part of the study warranted investigation beyond the total natural gas and electricity intensities. First, the base (weather-independent) component and the variable (weather-dependent) component of the natural gas and electricity consumption were identified.

Additionally, the buildings were classified according to the primary heating system type. 


\subsubsection{Base Load Determination}

Two methods were used to determine the base load component. The first method used was the Y-intercept from the weather normalization as shown in Figure 2.

The second method used was the average between the two lowest months of energy consumption to estimate the base load. For natural gas loads, the two months of lowest consumption were typically July and August. For electrical loads in buildings with air conditioning, April and October were typically the lowest. Generally, the "Y-intercept Method" was preferred but the "Low Average Method" was used for buildings exhibiting a relatively low $\mathrm{R}^{2}$ value in the weather normalization because the $\mathrm{Y}$-Intercept was deemed less certain. Base and variable electricity consumption were determined using the Y-intercept method on the best of the three correlations between electricity use and HDD and CDD as described in Section 3.1.

\subsubsection{Heating System Type Determination}

Buildings were classified according to primary heating system type to ensure that like-to-like comparisons were made between the buildings within the Refined Data Set.

Toronto is a heating-dominated climate therefore the most significant contributor to variable, or weatherdependent, load is space heating. So, to verify the heating system information provided in the audit reports, the weather-dependence of variable heating and electricity use was plotted against one another, as shown in Figure 3.

Buildings with high variable natural gas intensity and low variable electricity intensity were assumed to have natural gas heating. Natural gas is the primary fuel source used in Toronto because it is readily available and more economical than using electricity for space and domestic hot water heating. As expected, the majority of buildings in the study were classified as natural gas heating. Some building data included details of the type of natural gas heating system - hydronic, radiators or fan coil units. However, some buildings, with high variable electricity loads and low variable natural gas loads were assumed to use electricity for the primary heating system, also shown in Figure 3. Buildings with relatively low variable energy intensities in both energy source categories were classified as combination systems. Therefore, buildings were allocated to one of three groups: natural gas heating, electric heating, or a combination of both. 
Additionally, some buildings also had air-conditioning which was either suite-based or centrally supplied. The presence of air-conditioning in a building was determined based on the results of a correlation between total electricity use and CDD. If the correlation coefficient was greater than 0.5 , it was assumed that the building had air conditioning.

Using the findings from Figure 3 and the correlations between electricity use and CDD for each building, the heating system type and presence of air-conditioning were determined. Table 1 summarizes the number of buildings assigned to each category.

\section{$4 \quad$ Results and Discussion}

After completing the data processing, the building energy use data from the different sources could be directly compared. A discussion of the energy intensity of the data sets and a selection of the most significant correlations are presented here.

\subsection{Energy Use}

Figure 4 shows the weather-normalized energy intensity for each building in the data sets, with an average of $300 \mathrm{ekWh} / \mathrm{m}^{2}$. The worst performing buildings (grouped as the highest $10 \%$ of energy users) used more than three times the amount of energy consumed by the best performers (lowest $10 \%$ of energy users). This indicates a high level of variability in the data sets. However, there is some uncertainty as to whether the energy data of the two best performers, in particular, are complete given the extremely low energy intensity of these buildings.

The range in energy intensity may reflect a variety of factors. These factors include differences in the way the buildings are operated, in the efficiency of the major mechanical and electrical systems, and in materials and methods used to construct the building envelope.

A study of building energy use in New York City assessed annual energy intensity in a similar way [16]. The authors of the New York study suggested that the buildings with the highest energy intensities could achieve significant reductions in energy use through low-cost means such as adjusting controls, sensors and schedules of mechanical equipment. They estimated the impact of this change by considering a few different energy reduction scenarios. 
Based on their findings, it is believed that the highest energy intensity buildings from the Refined Data Set could achieve the median energy intensity of the sample through relatively inexpensive adjustments to building operations and maintenance. This assumes that the Refined data set sample is representative of the actual Toronto MURB population, which is discussed in Section 2.1, and that these low-cost energy-savings opportunities in New York City are similar to the opportunities available in the Toronto MURB stock. If these assumptions are true, simple energy conservation measures could reduce energy consumption of the entire Toronto MURB building stock by more than $10 \%$, as shown in Figure 5 . Going further, if all the buildings were able to achieve an energy intensity equivalent to that of the $75^{\text {th }}$ percentile, the total reduction in energy use would be more than $35 \%$.

Further research on the worst performers in the Toronto MURB stock is needed to determine what proportion of building energy use can be influenced by these operational changes.

Table 2 summarizes the weather-normalized minimum, maximum and average total annual energy intensity as well as the associated GHG emission intensity and the average energy source mix of each data set.

The average energy mix of the Refined Data Set (33\% electricity and 67\% natural gas) is only slightly different from the published energy mix of apartment buildings in Ontario: $34 \%$ electricity and $66 \%$ natural gas [19]. The GHG emission intensity figures together with average building size and number of MURBs are consistent with another published estimate which reported that Toronto MURBs erected between 1945 and 1984 were responsible for between $2.0 \mathrm{M}$ and $2.2 \mathrm{M}$ tonnes of $\mathrm{eCO}_{2}[20]$.

Generally, the results of this analysis are in line with existing studies [5-8] when weather-normalization procedures are considered. Figure 6 shows the average, maximum and minimum energy intensity for the other Toronto and Ontario studies discussed in Section 1.3 along with the average HDD for the years from which the energy data were taken. Disparities between this study and others are due, in part, to differing weather normalization practices. The data in this study were normalized to the CWEC standard weather year in order to directly compare buildings with data from different years. As discussed in Section 3.1, this standard year is based on the average weather data in Toronto for a 30-year time period from 1960-1989. This standard weather year is colder or warmer than the base years used in other studies. For example, the CWEC has over $20 \%$ more heating degree days than the average from 1990 to 2011 . The authors are currently developing a Heating Climate Index 
$(\mathrm{HCl})$ to transform standard weather year data to an approximation of actual energy use in a given year without repeating the weather normalization process from the original data.

\subsection{Correlation between Building Characteristics and Energy Use}

With the normalized energy intensity data compiled, correlations with various building characteristics were sought. The Meta-Analysis Data Set included only basic properties such as building height and vintage while the Refined Data Set included more detailed data such as envelope characteristics and mechanical system details. A selection of the most significant correlations from each data set is presented here.

\subsubsection{Meta-Analysis Data Set}

The aim of this study was to associate energy intensity with building typologies. As architectural typologies are typically associated with a particular time period, the authors felt that the most appropriate correlation analysis was between building energy use and date of construction. Figure 7 shows the results of this correlation. Average energy intensities decreased from older to younger buildings until the 1970 s, as indicated by the horizontal line in each decade. From the 1970s to the 1990s, average energy intensities then started to increase slightly.

The higher energy intensities of the oldest buildings in the data set could be due to the age of the mechanical systems and the condition of the building envelope. However, the increased energy intensities in the newer buildings may be due to the energy-saving effects of better thermal insulation and air-tightness measures being offset by higher fenestration ratios. This trend of increasing fenestration ratios was later confirmed with data obtained for the Refined Data Set, as shown in Figure 8.

Increasing fenestration ratios may explain the apparent paradox of the declining energy-efficiency of the more modern MURBs in the data set. This issue is being addressed by new codes and standards such as the Toronto Green Standard and 2012 Ontario Building Code requirements.

No correlation could be found between energy intensity and gross floor area, number of suites or building height. Naturally, the total building energy use increases with size, however the correlation between energy intensity and building size is not strong enough to suggest a trend even when buildings are classified by vintage or ownership type. The lack of correlation is likely due to the significant variation of the energy intensity data as 
previously shown. This finding suggests that if policy makers want to set certain energy intensity benchmarks or energy performance standards, different benchmarks for high-rise, mid-rise, and low-rise MURBs may not be required. However, this finding differs from another study based on Canada-wide HiSTAR data only [8] which showed that buildings between 7 and 20 stories were the most energy intensive group.

Investigation of the Meta-Analysis Data Set also included an exploration of the relationship between ownership type and energy intensity. On a gross floor area basis, privately-owned condominiums had the lowest average energy intensity, but on a per suite basis, they had the highest energy intensity as shown in Figure 9.

This difference in energy intensity, depending on the normalization method (by suite or area), can be explained by considering a few different factors. First, condominium buildings typically have larger suite sizes and thus presumably a lower occupant density, which explains the lower area-based energy intensity. However, when viewed on the suite basis, the higher energy intensity can be attributed to generally higher incomes and therefore more household appliances and electronics. It can also be attributed to the greater common area loads often seen in condominiums such as pools and gyms. As well, with larger suites, common area energy use is spread over a smaller number of units. The energy intensity of the subsidized rental buildings on both the 'per area' and 'per suite' basis was lower compared to the other ownership types. This can perhaps be explained by restricted operating budgets and limited common areas, typical for this ownership type.

In addition to examining how energy intensity is influenced by building characteristics, a correlation between attributed suite size and construction date was sought to see if generalizations could be made how suite size has changed over time, as shown in Figure 10.

From the oldest buildings in the data set to the 1980's, the average attributed suite size increased. However, in recent years, the data reveal the prevalence of smaller suite sizes. This could be influenced by the size of common areas, the actual suite sizes or both.

\subsubsection{Refined Data Set}

Within the Refined Data Set, buildings were first grouped according to heating system type to ensure a like-to-like comparison. Variables relating to the mechanical and electrical system, the building envelope, and the occupancy characteristics were then examined to determine their influence on energy intensity. First, these 
individual variables were tested against various measures of energy use (normalized by suite or area) to determine where correlations existed. The correlations revealed the expected results but with weaker correlation coefficients than anticipated. A selection of the correlations is presented here.

Since the majority of heat loss and solar heat gain through the building envelope is through the glazing, it was expected that the larger the fenestration ratio, the greater the resulting heating and cooling loads. This expected relationship is revealed Figure 11. The relationship, with respect to natural gas consumption, appears to be stronger in buildings with double-glazed windows than with buildings with single-glazed windows. This stronger correlation with double-glazed windows is shown by the higher correlation coefficient in Figure 11.

It is possible that the $R^{2}$ value for single-glazed windows was lower than the $R^{2}$ value for double-glazed windows because single-glazed windows are generally older and the glazing units are in worse condition. Thus, the air-tightness of the glazing assemblies may be a significant factor that governs heat loss for these buildings, not just the fenestration ratio. Similarly, a higher fenestration ratio also leads to greater air conditioning loads $\left(R^{2}=\right.$ 0.58 for variable electricity intensity versus fenestration ratio for double-glazed window). This is expected because of solar gains as well as conductive and convective heat gains from the outdoors during the summer.

Glazing thermal conductance (U-value) is another factor contributing to heating and cooling loads. Higher U-values mean that more heat transfer occurs and thus heating and cooling loads will presumably be higher. This was confirmed for both heating and cooling albeit, the heating condition showed a weaker correlation. The stronger correlations shown with fenestration ratio suggest that glazing area has a greater effect on heating intensity than window thermal conductance.

Another factor affecting building heating loads is the efficiency of the heating system. It was expected that the more efficient the heating system, the lower the resulting variable natural gas intensity. However, the relationship between variable natural gas intensity and boiler efficiency, as shown in Figure 12, was not as strong as expected. This may be due to the fact that the boiler efficiencies provided in the audit reports may not reflect the actual efficiency of the heating system. Therefore, while the approximate relationship is correct, the correlation could be stronger with data that better reflects the actual performance of the system. 
The provided boiler efficiencies are either rated or estimated. The rated efficiency is intended to be an indication of the efficiency of the boiler when it was new; however, it is possible that this efficiency was never achieved. Also, as the boiler ages, efficiency declines. The rate of decline depends on maintenance practices, the boiler use patterns, the type of boiler, and the boiler and pipe configuration. The influence of boiler age on variable natural gas intensity was also investigated but resulted in a similarly weak correlation, likely due to the wide range of factors affecting boiler efficiency.

Therefore, for some of the variables such as boiler efficiency and fenestration ratio, the correlation coefficient was found to be low because the data may not always reflect the actual conditions of the building. For other variables such as the thermal conductance of the glazing, it was speculated that a different building characteristic such as glazing air-tightness may govern the energy-use relationship instead. However, this hypothesis could not be tested since no data relating to glazing air-tightness were available.

As discussed above, the correlations between energy use components and single building characteristics were lower than expected. Given the systems-based interaction between building components, the authors believed that considering a group of explanatory variables, instead of one variable at a time, may better explain the range of energy intensities across the building stock. Therefore, a multi-variable regression analysis was conducted to determine the influence of a combination of variables.

Prior to conducting the multi-variable regression analysis, predictions were made regarding the variable groupings that would have the most significant effect on different components of energy use. These predicted groups or those variables were expected to emerge as the most influential for a particular energy use component are shown in Table 3.

The correlation coefficients remained low in the multi-variable linear regression models conducted for the various components of energy intensity. Similar to the correlation analysis, the multi-variable regression analysis was also limited by the type and quality of data available.

Finally, buildings that were significantly different from the identified trends were examined in greater detail to determine the reasons for the anomalies. The analysis of anomalies revealed that although there was not one 
particular factor that could explain a large group of the anomalies, information on the special facilities, such as a pool or on-site daycare included in the buildings, aided in the explanation of a number of the anomalies.

\section{Conclusions and Recommendations}

This study revealed a wide range in energy intensities of Toronto MURBs and that typology-specific energy-use trends could not be established. Nevertheless, a series of interesting observations and conclusions are presented here including recommendations that could be adopted by future researchers as well as policy makers.

\subsection{Data set characteristics}

The data sets represented the population reasonably well in terms of the division between low-rise and mid- and high-rise however some vintage categories were over-represented due to one of the data sources being based on the newer condominium market. Based on the analysis conducted, there did not appear to be any correlation between energy intensity and building height or size.

Recommendation: Specific policies for different building size groups may not be needed.

\subsection{Energy Intensity Data}

The observed energy intensities were highly variable. With this wide range attributed to differences in the way the building is operated, it was suggested that many buildings can realize significant improvements in energy performance by changing operating procedures. Further research is needed to refine the estimated impact of this improvement in the Toronto MURB population but more data is required to do this.

Recommendation: The City of Toronto should require reporting of energy-use data and the associated building characteristics. This can either be triggered by the sale or rental of a property [21] or through participation in a retrofit funding scheme. Alternatively this information can be required of all buildings annually [16]. Data can be collected by the property owners or this process can be automated by seeking permission to access smart meter data directly from utility providers. Any required reporting must establish reporting guidelines so that data are collected in a uniform manner for straightforward integration into a building energy-use database. Additionally, all energy audits undertaken on a voluntary basis should include explicit information on how data, such as conditioned 
floor area, were calculated or a reference to the standard audit guideline followed. Any estimates or assumptions should also be clearly stated and justified.

\subsection{Energy Mix}

Toronto MURBs have significantly higher natural gas intensities compared with electricity intensities, as is the case for most of the residential built environment in the Toronto area.

Recommendation: To significantly reduce the GHG emissions associated with the MURB sector, natural gas savings measures should be promoted.

\subsection{Correlation Analysis}

Generally, the energy intensity trends observed in this study were as expected. However, the influence of individual building characteristics was not as certain as anticipated.

The energy intensity of buildings decreased with date of construction up until the 1970s when energy intensities began to increase again. This declining energy efficiency may be explained by increased fenestration ratios offsetting the gains of better air-tightness and envelope thermal resistance. To support this explanation, relatively strong correlations between fenestration ratio and variable natural gas intensity were found as well as increasing fenestration ratios in newer buildings. However, the fenestration ratio is a variable that cannot be easily altered in an existing building. Thankfully, this challenge has recently been addressed by the introduction of the new Ontario Building Code in 2012.

Heating system efficiency, second only to glazing characteristics such as fenestration ratio, is the variable most closely linked to energy intensity. However, the lower-than-expected correlation coefficient between variable natural gas and boiler efficiency could indicate that efficiency estimates of existing boilers are either not accurate or that boiler efficiency does not inadequately describe the performance of the heating system as a whole.

Recommendation: A cost-effective method for determining more accurate mechanical system efficiencies should be developed. 


\subsection{Weather Normalization}

Using a 'standard weather year' is a rational way of making energy comparisons between various building studies. Many researchers and consultants have already relied heavily on the use of the CWEC standard weather year; therefore, there are compelling reasons for continuing this approach of weather normalization. However, using the standard weather year to predict energy savings from retrofit measures may lead to erroneous results in periods of changing climate or microclimate. Of particular concern is the risk of under- or over-stating savings due to retrofit.

Recommendation: Develop an approach to normalization such as a Climate Index that is referenced to the standard weather year. Similar to the Consumer Price Index, an Index Value 1.0 could be assigned to the CWEC standard weather year, and other weather periods could be assigned a corresponding Index Value. With a system like this in place, data from different sources can be readily compared using different reference time frames depending upon the desired outcome of the investigation.

By adopting the recommendations outlined, the body of data on MURB energy use and building characteristics will be improved so that researchers can develop a more accurate and complete picture of the energy performance of MURB stock in Toronto. By furthering the work presented here, policy makers will have the information they need to efficiently target the highest energy intensity buildings thus maximizing the impact of energy conservation spending to reduce the impact of this sector.

\section{Acknowledgements}

The authors gratefully acknowledge the funding provided by the Toronto Atmospheric Fund and the Hutcheon Bequest. A special thank you to Bryan Purcell for his thorough review and thoughtful comments.

\section{References}

[1] M. McClelland, G. Stewart and A. Ord, Reassessing the Recent Past: Tower Neighborhood Renewal in Toronto, APT Bulletin: Journal of Preservation Technology vol. 42 (2011) 2-3.

[2] C. Binkley, M. Touchie, K.D. Pressnail, Energy Consumption Trends of Multi-Unit Residential Buildings in the City of Toronto, Toronto Atmospheric Fund (2012) unpublished. 
[3] ICF International, Greenhouse Gases and Air Pollutants in the City of Toronto, (2007) [Online] Available: http://www.toronto.ca/teo/pdf/ghg-aq-inventory-june2007.pdf

[4] City of Toronto, Change is in the Air: Toronto's Commitment to an Environmentally Sustainable Future, (2007) [Online] Available: http://www.toronto.ca/legdocs/mmis/2007/ex/bgrd/backgroundfile-2428.pdf

[5] D. Hart, Energy and water consumption load profiles in multi-unit residential buildings, Technical Series 05-119, Research Highlights Canadian Mortgage and Housing Corporation, 2005.

[6] Enermodal Engineering Limited, Review of OHC Building Energy and Water Audits, Technical Series 00-110, Research Highlights Canadian Mortgage and Housing Corporation, 2000.

[7] A.H. Elmahdy, Building Research Note: Annual Consumption Data on Apartment Buildings, Division of Building Research, National Research Council of Canada, Ottawa, 1982.

[8] R. Liu, Energy consumption and energy intensity in multi-unit residential buildings (MURBs) in Canada, Canadian Building Energy End-Use Data and Analysis Centre, 2007.

[9] G. Finch, E. Burnett, W. Knowles, Energy Consumption in Mid and High Rise Residential Buildings in British Columbia, Proceedings of Building Enclosure Science and Technology Conference, Portland, OR, 2010.

[10] I. Danielski, Large variations in specific final energy use in Swedish apartment buildings: Causes and solutions, Energy and Buildings, vol. 49 (2012) 276-285.

[11] Y. Choi, S.H. Cho, J.T. Kim, Energy Consumption Characteristics of high-rise apartment buildings according to shape and mixed-use development, Energy and Buildings, vol. 46 (2012) 123-131.

[12] City of Toronto, Toronto Plan, FlashForward Addendum: Projecting Housing Demand by Tenure to 2031, 2006.

[13] E. Tzekova, K.D. Pressnail, D. De Rose, K. Day, Evaluating the effectiveness of energy-efficient retrofits on multi-unit residential buildings: two case studies, Proceedings of $13^{\text {th }}$ Canadian Conference on Buildings Science and Technology, Winnipeg, MB, 2011.

[14] Arup, Community energy plan for pilot sites (2010) [Online] Available:

http://www.toronto.ca/city_manager/pdf/tr_arup_cep.pdf

[15] N.B. Hutcheon, G.O.P. Handegord, Building Science for a Cold Climate, Institute for Research in Construction, 1995. 
[16] New York City Mayor's Office, New York City Local Law 84 Benchmarking Report (2012) [Online] Available: http://www.nyc.gov/html/gbee/downloads/pdf/nyc_II84_benchmarking_report_2012.pdf [17] Environment Canada, National Inventory Report 1990-2008 (2010) [Online] Available: http://www.ec.gc.ca/Publications/default.asp?lang=En\&xml=492D914C-2EAB-47AB-A045-C62B2CDACC29 [18] Environment Canada, National Inventory Report 1990-2010 (2012) [Online] Available: http://www.ec.gc.ca/publications/default.asp?lang=En\&xml=A91164E0-7CEB-4D61-841C-BEA8BAA223F9 [19] Natural Resources Canada, Table 38: Apartments Secondary Energy Use and GHG Emissions by Energy Source, 2008.

[20] G. Stewart, J. Thorne, Tower neighbourhood renewal in the greater golden horseshoe: An analysis of high-rise tower apartment neighbourhoods developed in the post-war boom (1946-1984) (2010) [Online] Available: http://www.cugr.ca/tnrggh

[21] The National Archives, The Energy Performance of Buildings (Certificates and Inspections) (England and Wales) Regulations 2007 (2012) [Online] Available: http://www.legislation.gov.uk/uksi/2007/991/contents/made 


\section{Figure Captions}

Figure 1: Comparison of the height and vintage of the building sampled compared with the Toronto MURB population

Figure 2: Determination of base load component of building natural gas consumption through Y-Intercept Method

Figure 3: Determination of primary heating fuel source based on the variable natural gas and electricity intensity of each building

Figure 4: Total annual energy intensity of the sampled buildings

Figure 5: Project impact of energy consumption reductions on the Refined data set

Figure 6: Energy Intensities from various studies

Figure 7: Influence of building vintage on energy intensity

Figure 8: Changes in Fenestration ratio with building vintage

Figure 9: Influence of ownership type on energy intensity

Figure 10: Changing attributed suite size with building vintage

Figure 11: Influence of fenestration ratio on variable natural gas intensity

Figure 12: Influence of boiler efficiency on variable natural gas intensity 